\title{
A escola e as normas em conflito: um ensaio sobre a educação institucionalizada e direitos humanos
}

\author{
Rodrigo Manoel Dias da Silva*
}

\begin{abstract}
Resumo
O presente ensaio pretende realizar uma análise sobre a construção das normas sociais em instituições de ensino, evidenciando seus conflitos e descontinuidades na produção da justiça escolar. Através de estudo teórico, o autor interessa-se em discutir sociologicamente as implicações entre a escola e os princípios de justiça que orientam as políticas de direitos humanos, na contemporaneidade. Conclui reiterando que a proposição de uma política de direitos humanos, com efetividade no cotidiano escolar, precisa problematizar o regime meritocrático de organização escolar, considerando as múltiplas lógicas de ação política que a constituem.
\end{abstract}

Palavras-chave: escola, normas sociais, direitos humanos, justiça escolar.

L'essentiel de la sociologie de l'éducation contemporaine a choisi de se constituer à partir des problèmes de l'école

(DUBET, 2003, p.64).

\section{Introdução}

Nas últimas duas décadas acompanhamos um conjunto de transformações sociais, políticas, econômicas e culturais, as quais foram redefinindo as agendas investigativas em Sociologia da Educação. Aos poucos, as discussões foram derivando a temas que implicavam a percepção das novas dinâmicas da sociedade contemporânea que foram produzindo novas formações sócio-

Professor de Sociologia e Política na Universidade Federal da Fronteira Sul (UFFS),

Campus Erechim/RS. Endereço eletrônico: rodrigo_ddsilva@yahoo.com.br. 
culturais, situadas entre as redefinições do papel do Estado e a emergência dos imperativos do mercado nos espaços educacionais (BALL, 2001). No caso brasileiro, no fim dos anos de 1980, o pensamento sociológico em questão não somente desprendia-se de algumas ferramentas teóricas reprodutivistas, formuladas por Pierre Bourdieu, para pensar a escola, como abdicava gradativamente da própria escola como objeto sociológico de estudo. O que, em boa medida, acompanhava uma tendência iniciada em outros contextos, sobretudo no francês (DUBET, 2003).

A partir das mutações societárias em vigor (TIRAMONTI, 2005), novos temas foram sendo incorporados à Sociologia da Educação, por vezes estendendo o debate para além de seus limites empíricos, por outras se utilizando de novos referenciais teóricos de leitura da realidade. Esta sociologia adentrava em novas searas. Os estudos, portanto, passaram a abordar as novas espacialidades e territorialidades da educação, os estudos da mídia e seus dispositivos pedagógicos, os processos educacionais informais ou nãoescolares, as pedagogias e exercícios pedagógicos de movimentos sociais rurais e urbanos, os estudos de gênero, as leituras étnicas e os aprendizados sociais destas coletividades, os processos políticos de formação da juventude urbana, a questão da violência e outras temáticas político-pedagógicas de nossos tempos. Estes temas oportunizaram uma significativa multiplicação dos estudos sociológicos, sobretudo por alargarem a visão sobre os processos educativos e por demonstrarem algumas vinculações entre dinâmicas endógenas e exógenas na mudança social ${ }^{1}$ inerentes às próprias dinâmicas de ensino e de aprendizagem.

Mas, em perspectiva controversa, muitas das análises realizadas deixaram de evidenciar as imbricações destas mudanças societárias com a educação institucionalizada na/pela escola. O que hoje certos sociólogos têm observado como lacunar nesse campo de estudo. Essa constatação atualiza a leitura de Antônio Cândido, o qual reiterava nos anos de 1950:

1 A esse propósito, Valade (1995) recupera algumas contribuições sociológicas para compreender matizes do conceito de mudança social. 
Não seria possível, nem desejável, reduzir a sociologia educacional a uma sociologia da escola; mas parece conveniente considerá-la como o seu eixo, no estado atual dos problemas e dos estudos (CÂNDIDO, 1987, p.17).

Cândido denota a palavra 'eixo' um sentido produtivo para pensarmos a educação contemporânea, qual seja: a ideia de centralidade. Assim, o centro das análises sociológicas sobre os processos educacionais se encontraria na escola, pois assim poderíamos definir seus agrupamentos, papéis, relações e formações culturais. O sociólogo brasileiro nos ajuda a perceber as lacunas da produção acadêmica na atualidade, visão esta que se faz compartilhada por François Dubet (2003), ao mencionar, na epígrafe do presente ensaio que a sociologia educacional deve voltar-se novamente à escola.

Alain Touraine (2007), ao pensar as relações entre o sujeito e a escola, destaca:

É preciso voltar-se antes de mais nada para a escola, pois se trata de um setor da vida social onde se confrontam não apenas ideias mas também opções feitas pelos próprios professores e pelos pais de alunos, convencidos de que a opção de uma escola tem efeitos profundos e duradouros sobre toda a vida de seus filhos (TOURAINE, 2007, p.152).

O que há em comum entre os apontamentos de Antônio Cândido, Alain Touraine e François Dubet, mesmo temporal ou contextualmente distantes? Os três veem a escola como um espaço institucional definidor das relações sociais contemporâneas, produtor de sujeitos sociais e locus de mediações sociais e políticas - constituindo lugar próprio para analíticas da escola hodierna. Essas interpretações da realidade encaminham à constatação de que as instituições de ensino, mesmo em processo de mudança (TIRAMONTI, 2005), são mediadoras das relações atuais entre o ensino e a aprendizagem visibilizados nos processos de socialização (LOPES, 2009).

Diante desse horizonte teórico, estamos interessados, nesse ensaio, em realizarmos uma análise sobre a construção das normas na educação institucionalizada, evidenciando seus conflitos (VAN VELSEN, 1987) e descontinuidades (SILVA, 2008) na produção da 
justiça escolar. Optamos, portanto, em desdobrar esta proposição ao realizar um breve estudo sobre as implicações sociológicas entre a escola e os princípios de justiça que orientam as políticas de direitos humanos na contemporaneidade.

Diante desta proposição, organizamos didaticamente o presente ensaio em três seções textuais. Na primeira, apresentaremos algumas abordagens sociológicas sobre a escola como uma instituição social, recuperando leituras clássicas sobre o tema, desde Durkheim. Na segunda, apontaremos problematizações à construção das normas na escola e suas correspondências aos processos societários vigentes. Na terceira, diante do princípio de descontinuidade das normas escolares, produziremos uma análise das relações entre educação e direitos humanos tensionando, especificamente, suas lógicas e princípios de justiça.

\section{Escola como instituição social}

Nas perspectivas sociológicas clássicas, a escola é uma instituição socializadora, que define $o$ ator social por sua potencialidade em incorporar os valores e normas da sociedade de seu tempo. $\mathrm{O}$ ator incorpora os princípios estáveis e homogêneos do sistema, logo o ator é o sistema (DUBET, 1994). Mesmo perspectivas de orientação crítica não negam a condição de socialização das instituições de ensino, mas é na vertente funcionalista que estas afirmativas encontram sua origem e seu desenvolvimento mais evidenciados. É o que apresentaremos ao longo desta primeira seção textual: a escola e sua institucionalidade na produção dos atores sociais.

Apesar de considerar a definição de educação de Kant, de certa forma, idealista, Émile Durkheim não a remove plenamente de seu horizonte de preocupações investigativas. Segundo Kant, o fim da educação seria o desenvolvimento, em cada indivíduo, de toda perfeição de que este seja capaz. Na visão kantiana, perfeição é o desenvolvimento harmônico de todas as faculdades humanas (DURKHEIM, 1987).

Pela leitura de Durkheim, a sociedade não existiria sem que houvesse em seus membros certa homogeneidade, sendo função da educação a perpetuação e o reforço dessa homogeneidade, o que 
implicaria a fixação na criança de algumas similitudes necessárias à vida coletiva. Ao mesmo tempo, sem um mínimo de diversificação toda cooperação ou forma de solidariedade seria impossível: é a diversificação que permite a especialização da sociedade. Essa, portanto, seria a definição central do processo de socialização no quadro do Funcionalismo: a presença das funções diferenciadora e homogeneizadora das relações sociais. Assim sendo, educação:

É a ação exercida pelas gerações adultas sobre as gerações que não se encontram ainda preparadas para a vida social; tem por objeto suscitar e desenvolver, na criança, certo número de estados físicos, intelectuais e morais, reclamados pela sociedade política no seu conjunto e pelo meio especial a que a criança, particularmente, se destine (DURKHEIM, 1987, p.42).

O mesmo pensador francês, em sua definição de educação, revelou ressonâncias das três características do fato social que enunciara anteriormente. Quando mencionou que a educação é uma ação exercida por uma geração sobre outra, denota sentidos de coercitividade; ao mesmo tempo, quando citou acima que a educação é a ação de desenvolver determinados estados em alguém imaturo, propôs elementos de exterioridade. Ao mencionar que o fenômeno educativo ocorre em um meio específico, reiterou seu caráter de objetividade. Assim, as demarcações de objetividade, coercitividade e exterioridade, típicas de sua noção de fato social, caracterizam sua acepção de educação. Além disso, a educação parece um processo linear, contínuo, de normas sociais homogêneas e produtoras de funcionalidades ao sistema social - o que denotaria o caráter social da educação.

As características do fato social de Durkheim são elementos significativos na definição de instituição social de Peter e Brigitte Berger. Oportunamente, recuperaremos agora essa definição, de modo que nos seja útil a proposição da escola como uma instituição social. Consoante à elaboração dos autores, partimos da ideia de que toda instituição social seja uma forma de objetivação da realidade, pois no fluxo das experiências sociais ela se torna dotada de exterioridade, objetividade e coercitividade, além de autoridade moral e historicidade (Berger; Berger, 1977). A exterioridade 
refere-se ao fato de uma instituição social ser experimentada como algo dotado de realidade exterior ao indivíduo, ou seja, fora do indivíduo, diferindo-se da realidade formada por seus sentimentos, pensamentos ou fantasias. A objetividade, por sua vez, refere-se à existência material da instituição.

As instituições são dotadas de força coercitiva:

Em certa medida, esta qualidade está implícita nas duas que já enumeramos: o poder essencial que a instituição exerce sobre o indivíduo consiste justamente no fato de que a mesma tem existência objetiva e não pode ser afastada por ele. No entanto, se acontecer que este não note o fato, esqueça o mesmo ou, o que é pior -, queira modificar o estado de coisas existente, é nessas oportunidades que muito provavelmente a força coercitiva da instituição se apresenta de forma bastante rude (BERGER \& BERGER, 1977, p.197).

A dimensão coercitiva da instituição caracteriza-se pela garantia da homogeneidade da ordem social. O que não significa que não ocorram mudanças, as instituições mudam constantemente para garantir seus resultados de ação e controle. Esse efeito de manutenção não se dá unicamente pela coercitividade, mas por sua autoridade moral. Toda instituição social exige seu direito à legitimidade, reservando-se ao direito de repreender o indivíduo que viola suas normas e regras morais. Essa última caracterização das instituições sociais, a nosso ver, revela uma fissura com o marco funcionalista, pois propõe que a instituição tem a qualidade da historicidade, não constituída apenas por fatos, mas por fatos históricos.

A definição da escola como uma instituição social, além das características acima citadas, implica verificarmos sociologicamente elementos de sua estrutura, tal como realizaram Cândido (1971) e Znaniecki (1971). Quando, no fim dos anos de 1940, Florian Znaniecki indicava um caminho analítico à compreensão dos processos sociais ocorridos no seio das instituições de ensino, inaugurava uma nova e significativa linhagem de interpretação sociológica da escola como um grupo instituído. Tal concepção empregava o termo grupo instituído para designar, então, determinados agrupamentos que seriam, por excelência, produtos da cooperação entre seus membros, mas cujas posições e funções na coletividade seriam instituídos por 
outros grupos sociais (Znaniecki, 1971). Esta abordagem afirmava que o grupo instituído, necessariamente, não seria determinado por outro que fosse, nestes termos, o instituidor, mas teria um espaço de negociações entre ambos com provável prevalência do último.

Dentro do campo heurístico elaborado por Znaniecki, poderíamos tomar então a escola como referência, uma vez que "toda escola consiste num grupo social, com uma composição definida, e uma organização e uma estrutura, ainda que rudimentares" (idem, p. 105). Neste caso, sua existência dependeria das atividades associadas entre seus membros - genericamente - professores e alunos, o que determinaria seu caráter autônomo; mas, por vezes, a escola se faz sancionada por outros grupos sociais: o Estado, grupos religiosos, grupos territoriais ou diversos grupos culturais. Outras escolas, segundo o mesmo autor, são instituídas por determinadas categorias profissionais ou por grupos econômicos. Mas, em todo caso, destaca que:

[...] uma escola, enquanto grupo social, conserva um certo grau de autonomia interna, uma ordem específica própria, semelhante à de muitas outras escolas, mas diferentes da de grupos de uma outra categoria, pois o papel dos professores e dos alunos diferem essencialmente do papel dos membros de qualquer outro grupo (ZNANIECKI, 1971, p.106).

Alguns estudos posteriores recuperaram esta tese ao mencionarem que "os resultados escolares ainda dependiam mais da natureza das comunicações entre professores e alunos, o que remete diretamente ao ponto de vista dos atores e de suas interações" (TOURAINE, 2007, p.106). Em trabalho recente (SILVA, 2008), observamos que a perspectiva de Znaniecki, sobre a escola como grupo instituído, se torna analiticamente produtiva quando contrastada com a produção das sociabilidades no mesmo espaço social (CÂNDIDO, 1971). A ambiguidade entre a institucionalização e a produção das sociabilidades na escola produz brechas para a negociação das autonomias dos atores no âmbito destas relações sociais. Naquele quadro, afirmávamos que as políticas escolares, sobretudo aquelas atreladas à efetividade dos mecanismos de participação política, são constituídas em práticas culturais de negociação pelos usos 
destes espaços, o que implica formulação e definição de agendas por meio de mobilizações sócio-políticas. Embora a pesquisa tenha reafirmado o peso da institucionalização na definição destas agendas, pois se evidenciaram expressões de participação nãoautônomas nestas dinâmicas (SILVA, 2008), demarcamos que sua vigência não se assenta em princípios homogêneos ou contínuos, mas em lógicas de ação heterogêneas e diversificadas produzidas desde a experiência (DUBET, 1994) dos atores sociais envolvidos. Estes espaços de negociação (endógenos e exógenos) das normas escolares são produzidos quando supomos a conflitualidade das mesmas, objeto de análise da próxima seção textual.

\section{Normas em conflito e a educação contemporânea}

A análise sociológica das dinâmicas de produção dos processos escolarizados na contemporaneidade encaminha a reflexões em torno da socialização escolar. Em Durkheim (1987), como vimos, a socialização do ator é definida desde a incorporação das normas sociais, supondo a sociedade como uma entidade estável que lhe preexista e subsista, assim como as normas que sustentam essa entidade seriam homogêneas. Por outro lado, observamos que autores como Cândido (1971) e Znaniecki (1971), apesar de reconhecerem a superimposição das normas escolares, interpretam a escola desde mecanismos de negociação entre elementos endógenos e exógenos, dimensionando possibilidades de produção da autonomia dos atores nesses processos.

As compreensões de Cândido e Znaniecki, por um lado, se atualizam na leitura da noção de experiência social (DUBET, 1994), mas, por outro, exigem que alguns de seus argumentos sejam revisitados para que possamos vislumbrar algumas rupturas conceituais. Ao entendermos que o ator não está totalmente socializado, suspeitamos das versões funcionalistas de que a ação social seria redutível à versão subjetiva do sistema, pois:

Se o actor não está totalmente socializado, não é porque lhe preexistam elementos "naturais" e irredutíveis, a alma ou a razão, por exemplo, é porque a acção não tem unidade, não é redutível a um programa único (DUBET, 1994, p. 95). 
O que permite criticarmos aquelas noções de hiper-socialização, nas quais o ator seria um ente exclusivamente programado pelo sistema social, na acepção parsoniana, que não produziria sua identidade, sua autonomia ou mesmo contestaria a ordem vigente. Essa visão distingue ator de seu papel social. Mas, por outro lado, não o torna um ser clarividente capaz de compreender e dominar os esquemas de poder que o circundam, apenas revela-nos que a subjetividade dos atores é construída desde um conjunto incongruente de lógicas de ação. Não supondo a homogeneidade destas produções normativas, mas sim suas contradições, descontinuidades e conflitos (VAN VELSEN, 1987).

Por este viés da Sociologia da Experiência, que reconhece a incongruência das normas sociais e a fragilização dos princípios funcionalistas de leitura da sociedade, podemos pensar a educação contemporânea. As normas sociais são produzidas desde sua conflitualidade, desde a combinatória de várias lógicas de ação na experiência dos atores. Faz-se oportuno mencionarmos que por Sociologia da Experiência entende-se:

A sociologia da experiência tem em vista definir a experiência como uma combinação de lógicas de aç̧ão, lógicas que ligam o actor a cada uma das dimensões de um sistema. $\mathrm{O}$ actor é obrigado a articular lógicas de acção diferentes, e é a dinâmica gerada por esta actividade que constitui a subjectividade do ator e sua reflectividade (DUBET, 1994, p.107).

Ao reconhecermos que a experiência social, como objeto sociológico, é construída a partir da incongruência das lógicas de ação, decorrência da heterogeneidade das normas sociais, verificamos que o conceito exige três princípios weberianos de análise. Max Weber é o teórico da ação social significativa e da Sociologia Compreensiva, sua obra nos ajuda a interpretar o caso das normas sociais, sobretudo porque ele propõe uma tipologia da ação múltipla. Segundo o autor, não existiria um sistema e uma lógica de ação, mas uma pluralidade não-hierárquica de lógicas. Assim, compreendemos o primeiro princípio de análise: o fato da ação social não ter unidade. François Dubet afirma que a sociologia das religiões de Weber seria exemplar das tensões entre as lógicas/normas: 
A sociologia weberiana da religião está centrada no tema da 'tensão' entre lógicas diferentes: tensões entre os profetismos e a sua rotinização, tensões entre a fé e o capitalismo nunca inteiramente resolvidas... Cada actor adopta lógicas diferentes e, a par do pessimismo do desencantamento, quando domina a racionalidade instrumental,existe uma imagem mais analítica e mais dramatúrgica dos diversos tipos de acção (DUBET, 1994, p.109).

Neste horizonte, enquanto princípio, fixemos a diversidade analítica não-hierárquica de ação. O segundo princípio de análise diz que a ação é definida por relações sociais, diferindo-se da ideia de que a ação social seja definida apenas pelas orientações normativas e culturais dos atores. Isso implica pensarmos que a ação é uma orientação subjetiva, mas também uma relação. As lógicas de ação, possivelmente, sejam a articulação da subjetividade e dos princípios relacionais ${ }^{2}$. O terceiro princípio analítico informa sobre a experiência social enquanto combinatória - o que impõe algumas operações intelectuais. Uma delas, de ordem analítica, tem em vista isolar e descrever lógicas de ação presentes em cada experiência concreta. Em termos de Weber, vemos que uma experiência combina vários tipos puros de ação ${ }^{3}$ que importa distinguir, ao passo que estão inteiramente misturados no plano da experiência social, assim provavelmente a experiência não corresponda a um único tipo de ação.

Em estudo anterior (SILVA, 2008; 2009), utilizamos estes princípios para pensarmos as lógicas de ação política na educação contemporânea. Em termos antropológicos, essas lógicas de ação política (SILVA, 2008) se tornam elementos de descontinuidade dos princípios normativos que orientam a participação dos atores sociais, fazendo com que estes, além de identificarem os limites

2 Cumpre reconhecermos que estas relações sociais adquirem diversas tipicidades, na contemporaneidade. Na abordagem que ora realizamos, sobre as instituições de ensino brasileiras de nosso tempo, nas interfaces com os princípios de justiça que lhes são constitutivos, destaca-se que essas relações tendem a ser constituídas por modelos organizativos hierárquicos, com maior ou menor nível de autonomia de seus atores sociais.

3 Em Weber, "a ação social (...) orienta-se pelas ações dos outros, que podem ser passadas, presentes ou esperadas como futuras" (WEBER, 1977, p.139). Segundo o autor, a ação social pode ser: racional com relação a fins, racional com relação a valores, afetiva ou tradicional (idem, p.141). 
institucionais, reconheçam seu campo de possibilidades (VELHO, 1994). Parece-nos, portanto, que estas percepções investigativas podem servir de mote para realizarmos um debate sobre as novas temáticas que emergem das transformações sociais da atualidade, que se desdobram em processos institucionalizados de ensino escolar, quais sejam: justiça e direitos humanos na escola.

\section{Emergência de novas temáticas: justiça, educa- ção e direitos humanos}

Na primeira seção deste ensaio, apresentamos as dimensões institucionais dos processos educativos, recuperando elementos teóricos do Funcionalismo e parte de seu enfraquecimento; em seguida, na segunda seção, evidenciamos a descontinuidade das normas sociais e sua produção desde a combinatória de lógicas de ação, pelas lentes teóricas da Sociologia da Experiência. Diante das movimentações analíticas anteriores, nesse momento estamos interessados em evidenciar, empiricamente, alguns tensionamentos às normas escolares.

A questão dos direitos humanos na sociedade contemporânea está envolvida por interesses pedagógicos, ou de uma educação em direitos humanos (DALLARI, 2000; CANDAU, 2003; ESTEVÃO, 2006; CLAUDE, 2005). Ideologicamente, seus horizontes de preocupações políticas alinham-se ao anunciado por Dallari (2000):

Através da educação para os direitos humanos, os dominados, discriminados e excluídos adquirem consciência dos direitos inerentes à sua condição humana e começam a lutar por eles (p.26).

No entanto, quando descentramos esta perspectiva para a escola contemporânea, no Brasil, precisamos compreender que algumas práticas sociais aprofundam as relações de desigualdade, não constituindo uma agenda de redefinições dos dispositivos institucionais, tampouco são capazes de rever a educação em um tecido social impregnado de preconceitos (CANDAU, 2003). O debate torna-se produtivo quando discutimos um tensionamento central aos processos escolarizados: a incompatibilidade entre a 
igualdade de oportunidades escolares (de acesso, sobretudo) e a desigualdade de seus méritos. $\mathrm{O}$ que atualiza e dá centralidade às novas configurações da justiça escolar ${ }^{4}$.

O mérito parece ser um elemento indiscutível de mensuração dos resultados escolares, pois:

A priori, toda criança que entra na escola deve dispor das mesmas oportunidades de ter êxito escolar, independentemente de seu nascimento e de sua fortuna. A escola deve então construir uma competição justa a fim de que cada um obtenha o lugar que merece e que se forme assim uma ordem social justa (DUBET, 2008, p.383).

O que é colocado na pauta deste debate são os modos como operam os princípios de justiça na escola, particularmente observáveis no contexto, verificando inclusive as possibilidades e impossibilidades do conceito de justiça nestas situações. Pois se a escola constitui-se como um espaço das diferenças culturais, tal como as dinâmicas de seu tempo, é oportuno questionarmos sobre esta linearidade ou homogeneidade da igualdade de oportunidades. Sabe-se que este modelo de justiça escolar confere legitimidade moral $^{5}$ às desigualdades escolares (DUBET, 2005; 2008), que lhe são resultantes, sendo que, sob esta lógica, cada um pode ater-se ao seu desempenho e a si mesmo. O mérito passa a ser unidade de medida das individualidades e determina, inclusive politicamente, as práticas de participação estudantil na escola (Silva, 2008), como definiremos a seguir. Trata-se, portanto, de um princípio de justiça cruel para os indivíduos, ao passo que se faz exigência de processos políticos e administrativos, pois requer méritos individuais (DUBET, 2008).

Não seria crível uma escola de igualdade, porque mesmo a igualdade de acesso sendo garantida pela gratuidade do ensino, ainda assim o capital cultural das famílias, as estratégias, ambições dos pais quanto à educação, trajetórias de vida e biografias seriam distintas. Parece-nos, aqui, que quanto mais se intensifica a igual-

4 Para aprofundamento da discussão sobre os princípios de justiça, face à emergência da educação em direitos humanos, ver Estevão $(2001 ; 2006)$ ou, por outra perspectiva, González (2007).

5 Ou autoridade moral, conforme Berger e Berger (1977). 
dade de acesso, mais desigualdades pesam nestas proposições. A desigualdade das oportunidades escolares decorre, em alguma medida, das desigualdades sociais e culturais de fora da escola, o que não isenta a escola de produzir seus próprios dispositivos. O que provoca um paradoxo central aos fazeres escolares:

Tanto mais a escola é animada pelo princípio da igualdade de oportunidades, mais ela afirma que os indivíduos são livres e iguais, e mais ela se afunda numa contradição, pois ela é encarregada de classificar todos os alunos mantendo sua igualdade e sua dignidade fundamentais (DUBET, 2008, p.390).

Por esse olhar, há interesses políticos e mecanismos institucionais que mantém a escola sob este princípio de justiça, o que obstaculiza a efetividade de práticas democráticas e as inter-relações entre as diferenças culturais presentes na escola. Assim,

Por trás de cada debate escolar se percebem interesses mais tangíveis, pois não podemos esquecer que, no jogo geral das injustiças, certos grupos sociais 'ganham' enquanto outros 'perdem', e toda organização do jogo poderia distribuir de outra forma seus ganhos e suas perdas (idem, p.391)

E segue o autor:

Do ponto de vista democrático, toda dificuldade vem do fato de que os vencedores têm uma espécie de monopólio da palavra e da legitimidade, enquanto os perdedores se sentem inválidos e não podem nem querer empenhar a palavra. Esses desequilíbrios profundos acentuam as dificuldades dos menos favorecidos e a exclusão dos excluídos no seio de um modelo no qual continuamos convencidos de que as desigualdades produzidas na escola continuam, no fundo, profundamente justas (idem, p.391).

Uma situação que ilustra o apontamento realizado por François Dubet identificamos em estudo que realizamos (Silva, 2008). Na ocasião, investigávamos o alcance e a efetividade das práticas de participação política de estudantes na escola pública, em municípios do interior do Estado do Rio Grande do Sul, interessados em compreender seus modos de participar e, portanto, 
suas lógicas de ação política. Uma das categorias que elegemos para análise foi o modo como os estudantes eram escolhidos ou selecionados para as funções de liderança, dentro das possibilidades legitimadas pela legislação educacional daquele Estado, quais sejam: participação em grêmios estudantis, eleição para líderes de turma e representação junto ao Conselho Escolar (órgão colegiado, representativo, criado por lei estadual como instrumento de gestão democrática das políticas da educação). Não obstante aos discursos democráticos, ao entrevistarmos alguns atores destas instituições constatamos que seus representantes discentes eram escolhidos ou tinham sua eleição induzida de acordo com os méritos escolares dos estudantes, assim aqueles que dispunham de algumas características (como serem disciplinados, obedientes, estudiosos, dentre outras) tinham maiores possibilidades de ingressarem nos mecanismos instituídos de participação.

Pareceu-nos que, mesmo aberta às dinâmicas interacionais (CÂNDIDO, 1971), a escola fecha-se sob critérios de seleção de seus participantes. Estes critérios de seletividade operam, desde a 'conscientização para o voto', momento geralmente coordenado por um docente, até a retórica dos líderes eleitos que justificam sua escolha baseada em seus próprios méritos. Assim, identificamos que a participação política na escola pública pode ser uma expressão da desigualdade escolar e, mais especificamente, da desigualdade dos méritos escolares.

Portanto, se os processos de eleição são determinados pelas condutas e desempenhos escolares, podemos compreender que a participação política pode reforçar as desigualdades escolares e, em última análise, precisamos discutir o próprio princípio de igualdade - princípio este fundante daquilo que nomeamos como gestão democrática dos processos escolares institucionalizados.

\section{Considerações Finais}

A explicação sociológica sobre o processo de socialização, no quadro funcionalista, na qual o ator era tido como o sistema uma vez que incorporava homogeneamente suas normas e estatutos, 
definitivamente parece perder seu poder heurístico ${ }^{6}$. 0 ator constrói sua subjetivação, combinado a suas relações sociais, desde lógicas de ação múltiplas e incongruentes sob as quais elabora sua experiência social (DUBET, 1994). Nesse quadro de novas definições, as normas sociais não são mais lidas em sua linearidade ou homogeneidade, mas em suas descontinuidades (Silva, 2008) ou em seus conflitos (VAN VELSEN, 1987).

Essas posições teóricas permitem-nos um exercício de análise sociológica desde a escola, para compreendê-la institucionalmente, mas também para lermos a sociedade de nosso tempo a partir da escola. As experiências sociais produzidas na escola contemporânea são um mote interessante para pensarmos as lógicas de ação e os princípios de justiça em seu interior. O desafio que se projeta nestas relações, e que abordamos nesse ensaio, consiste em verificarmos as interfaces entre a educação escolarizada e as políticas de direitos humanos.

Naquilo que tange à abordagem que realizamos, observamos alguns tensionamentos às desigualdades escolares evidentes na incompatibilidade entre a igualdade das oportunidades escolares e a desigualdade dos méritos. A naturalização dos méritos individuais no contexto escolar constitui-se em obstáculo para o avanço de proposições mais igualitárias em seu espaço social, debate este central aos princípios de justiça dessa escola, de modo que, ocasionalmente, a própria participação discente na escola pareceu-nos regida por esta desigualdade dos méritos escolares (Silva, 2008). A proposição de uma política de direitos humanos, com efetividade no cotidiano escolar, precisa problematizar o regime meritocrático de organização escolar, considerando suas múltiplas lógicas de ação política.

Recebido em: 25.1.2010

Aprovado em: 10.8 .2010

6 No espaço escolar, Dubet (2007) destaca a fragilidade dos princípios estruturadores da instituição de ensino, quais sejam: valores sagrados, vocação docente, escola como santuário e liberação através da disciplina. Pela fragilização destes princípios, identifica o declínio institucional da escola. 


\section{Referências:}

BALL, S.J. Diretrizes Políticas Globais e Relações Políticas Locais em Educação. Currículo sem Fronteiras, v. 1, n. 2, p. 99-116, 2001.

BERGER, P.L.; BERGER, B.O que é uma instituição social? In: FORACHI, M.M.; MARTINS, J.S. Sociologia e Sociedade: leituras de introdução à sociologia. Rio de Janeiro: LTC, 1977.

CANDAU, V. (Coord.) Somos tod@s iguais? Escola, discriminação e educação em direitos humanos. Rio de Janeiro: DP\&A, 2003.

CÂNDIDO, A.A estrutura da escola. In: FORACCHI, M. M.; PEREIRA, L. Educação e Sociedade: leituras de sociologia da educação. 6⿳亠丷⿵冂⿱十口𧰨 ed. São Paulo: Companhia Editora Nacional, 1971.

CÂNDIDO, A. Tendências no desenvolvimento da sociologia da educação. In: FORACCHI, M. M.; PEREIRA, L. Educação e Sociedade: leituras de sociologia da educação. 13aa ed. São Paulo: Companhia Editora Nacional, 1987.

CLAUDE, R.P. Direito à Educação e Educação para os direitos humanos. SUR - Revista Internacional de Direitos Humanos, v. 2, p. 36-63, 2005.

DALLARI, D. Direitos Humanos, Exclusão Social e Educação para o Humanismo. In: PIRES, C.P.; KEIL, I.M.; ALBUQUERQUE, P.P.; VIOLA, S.E A. (Orgs.) Direitos Humanos, Pobreza e Exclusão. São Leopoldo: Adunisinos, 2000.

DUBET, F. Sociologia da Experiência. Lisboa: Instituto Piaget, 1994.

- Éducation: pour sortir de l'idée de crise. Éducation et Societés, n. 11, p. 47-64, 2003.

. La escuela de las oportunidades - ¿Qué es una escuela justa? Barcelona: Gedisa, 2005.

. El declive y las mutaciones de la instituición. Revista de Antropología Social, n. 16, p. 39-66, 2007.

- Democratização escolar e justiça na escola. Revista Educação, v. 33, n. 3, p. 111-124, 2008.

DURKHEIM, E. A educação como processo socializador: função homogeneizadora e função diferenciadora. In: FORACCHI, M. 
M.; PEREIRA, L. Educação e Sociedade: leituras de sociologia da educação. 13a ed. São Paulo: Companhia Editora Nacional, 1987.

ESTEVÃO, C. Justiça e Educação: a justiça plural e a igualdade complexa na escola. São Paulo: Cortez, 2001.

. Educação, justiça e direitos humanos. Educação e Pesquisa, v. 32, n. 1, p. 85-101, 2006.

GONZÁLEZ, M.R.G. Multiculturalismo y derechos humanos: limitar, tolerar o fomentar lo diferente. Andamios, v. 3, n. 6, p. 33-60, 2007.

LOPES, J.R. Antropologia, educação e condicionamentos culturais: pensando as mediações no processo de socialização escolar. Educar em Revista, n. 33, p. 171-188, 2009.

SETTON, M.G.J. A particularidade do processo de socialização contemporâneo. Tempo Social - Revista de Sociologia da USP, v. 17, n. 2, p. 335-350, 2005.

SILVA, R.M.D. Experiências sociais e lógicas de ação política: etnografia da participação estudantil na escola pública. Dissertação (Mestrado em Ciências Sociais). Universidade do Vale do Rio dos Sinos, 2008.

. O conceito de experiência social em François Dubet: possibilidades analíticas. Mediações, v. 14, n. 1, p. 275-290, 2009.

TIRAMONTI, G. La escuela en la encrucijada del cambio epocal. Educação e Sociedade, Campinas, v. 26, n. 92, p. 889-890, 2005.

TOURAINE, A. Um novo paradigma para compreender o mundo de hoje. São Paulo: Vozes, 2007.

VALADE, B. Mudança Social. In: BOUDON, R. (Org.) Tratado de Sociologia. Rio de Janeiro: Zahar, 1995.

VAN VELSEN, J.A análise situacional e o método de estudo de caso detalhado. In: FELDMAN-BIANCO, B. (Org.) A Antropologia das sociedades contemporâneas. São Paulo: Global, 1987.

VELHO, G. Projeto e metamorfose: antropologia das sociedades complexas. Rio de Janeiro: Zahar, 1994.

WEBER, M. Ação social e relação social. In: FORACHI, M. M.; MARTINS, J. S. Sociologia e Sociedade: leituras de introdução à sociologia. Rio de Janeiro: LTC, 1977. 


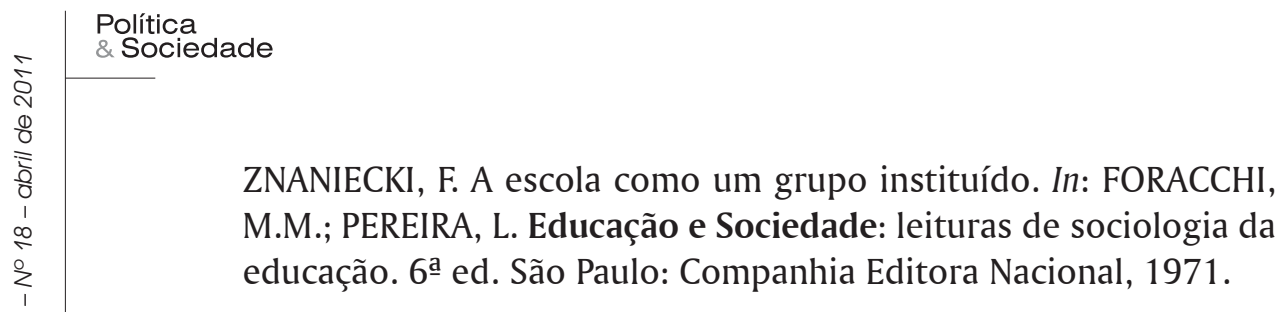

\begin{abstract}
Schools and norms in conflict: an essay on educational institutions and human rights

This article analyzes the construction of social norms in educational institutions, revealing their conflicts and discontinuities in producing justice within schools. Through theoretical study, we attempt to discuss the sociological implications of the principles of justice that guide human rights policies today, within the school context. We conclude by reiterating that the proposal for a human rights policy within the daily context of the school system should question the meritocratic system that presides within school organization, considering the multiple logics of the political action that constitutes it.
\end{abstract}

Keywords: school, social norms, human rights, school justice. 